\title{
The role of science in finding solutions to wicked, systemic problems
}

\author{
This article belongs to Ambio's 50th Anniversary Collection. Theme: Solutions-oriented \\ research
}

Erik Andersson

Published online: 14 March 2021

\section{WHAT IS THE ROLE OF SCIENTIFIC KNOWLEDGE?}

Why did solution-oriented research emerge and grow strong within Ambio? What was the identified need? Ambio's aims and objectives state that "Ambio particularly encourages multi- or inter-disciplinary submissions with explicit management or policy recommendations". While this certainly encourages solution-oriented research it does not sufficiently describe what solution-oriented research is. With its focus on the human-environment interactions Ambio has been a forum for discussing many multifaceted environmental issues, as is evident from the 50th Anniversary Collection of topics and studies. However, it is one thing to study and describe a complex real-world problem-actually solving it adds yet another layer of complexity. Finding solutions to wicked environmental problems is not a matter of simple technical fixes or command-and-control procedures, or even providing clear messages about problems and their causes; the solutions are often as complex as the problems themselves and require long-term engagement processes that involve realworld experimentation, collective learning, and continuous adaptation and reformulation of knowledge. As the contributions to this anniversary collection shows, the humanenvironment focus of Ambio lends itself well also for understanding problem context and exploring strategies for dealing with complex problems. Offering actionable solutions is a matter of providing guidance, examples, and ideally solid evidence for how to successfully intervene in sustainability problems in order to resolve or at least mitigate them (Lang and Wiek 2021).

Much of the research on environment-society interactions, and the use-inspired socio-environmental sciences more broadly, is based on the assumption that more knowledge about system dynamics is necessary for improved decision-making and action related to sustainability. This assumption has been increasingly questioned and critiqued since the 1980 s to early 2000 s when the anniversary articles were published-we have easier access to more information and new ways for communication, dialogue and collaboration. Yet, the scale and level of coordination needed to address issues like excessive use of nitrogen (Cassman et al. 2002), land degradation (Nepstad et al. 1991), misuse of the oceans (Folke and Kautsky 1989) or freshwater flows (Falkenmark 1989) and quality (Brix and Schierup 1989) are still challenging. Over time, the ideas for how to take knowledge to action have changed (Tengö and Andersson 2021; Lang and Wiek 2021). Earlier, the often-leading assumption was that action was embedded within the knowledge, i.e. such as creating knowledge specifically about which management action to take and how to implement it (Miller et al. 2014; Wiek and Lang 2016; Mach et al. 2020).

Over the years, many Ambio studies have taken extra steps to bridge science and practice. These steps include tailored, targeted output, identification of mediators/brokers, context specific action strategies, developing principles and identifying leverage points. To do this, authors have analysed both specific problems and the wider context they are embedded in and emerge from. Both the authors themselves and others have then built on this foundation to further operationalise early suggestions and recommendations.

\section{FROM PROBLEM TO PROBLEM CONTEXT}

Discussing the challenge of balancing food production needs against nutrition leakage and its adverse 
environmental effects, Cassman et al. (2002) pointed to the need for location and context specific solutions, which would both require better information. This includes quantitative understanding of current levels of $\mathrm{N}$-use efficiency and losses in these systems, and the biophysical controls on these factors, as well as the economic returns from adoption of improved management practices-and more effective ways for information uptake and implementation. As the authors now reflect (Cassman and Dobermann 2021), despite the promise in systematic agronomic approaches that harness (using e.g. Big Data and geospatial extrapolation frameworks to accelerate the process of optimising crop and soil management practices governing both yields and resource use efficiencies at production scale), implementation is slow. Overcoming this inertia would, the authors argue, require the implementation or strengthening of a number of wider, systemic enabling factors (ibid).

Similarly, Nepstad et al. (1991) argue that profitability is far from the only factor influencing the land-use decisions made, in their case by ranchers. They framed pasture as something that needs to be understood also as an argument in an ongoing discussion about what is deemed a socially acceptable or preferred land use, and in many cases ranching may also confer greater social status than competing land-uses (ibid).

Taking on water scarcity in Africa, Falkenmark (1989) identified governance structures and that would be required to improve overall water management, including the need-and approximate dimensions-for an overall (multi)national water strategy for socioeconomic development. Falkenmark argued for the need for cross-scale solutions, including international agreements for shared transboundary aquifers or rivers-and for including other measurements like population control in the strategies. She also identified knowledge tools that could support this reorientation of water management. Reflecting on her work after her 1989 paper (ibid) Falkenmark (2021) points to the importance of science-policy platforms and interfaces for taking scientific knowledge closer to practice.

\section{KNOWLEDGE TRANSFER, EXTENSION AND CO-CREATION}

Information in itself, however relevant or salient, may not suffice. It needs processing, uptake and endorsement from practice. One way to facilitate uptake and promote knowledge-in-use is to build communities of practice. Brix and Schierup (1989) outlined a 'bridging organisation', a group dedicated to establishing and maintaining a communication link between individual scientists working with scientific and technical aspects of using macrophytes for water pollution control and resource recovery. This group, they argued, would contribute to the coordination of research and development in the field, and promote exchange of results and thus reduce or prevent unnecessary duplication of efforts and expense.

Describing the long-term outcomes and impact of their 1989 article (Folke and Kautsky 1989) on aquaculture and the need for better governance of our oceans, Folke and Kautsky (2021) highlight the importance of filling gaps in our understanding of the role of aquatic foods in global food systems. They also reflect on the importance of science for change, and provide an example of trust-building collaborative effort with co-production of knowledge and understanding, drawing on the best science to date and combining it with competencies and skills of the transnational aquaculture and fisheries corporations to move towards common goals (Folke and Kautsky 2021). In this process, the researchers "serve as honest brokers, providing the state-of-the-art science to clarify, motivate and inspire the companies to perform towards sustainable ocean futures" (Folke and Kautsky 2021).

In their reflections on the state of the field and future challenges, Tengö and Andersson (2021) and Lang and Wiek (2021) describe the roles science and research can and will have in a broader exploration of actionable solutions. In essence, they argue, while scientific knowledge is vital for tackling the many complex and profound problems and challenges we are facing, perhaps it is rather a reframed scientific practice we should look to for finding real-world 'solutions'? One of the most important insights from recent work on knowledge interfaces and joint learning processes is that both knowledge needs and processes for actively create and develop knowledge differ across situations and contexts. Thus, assessing and adapting to the context is critical to achieve active learning and for putting knowledge to use (Tengö and Andersson 2021). Deeper, richer and more continuous dialogues between scholars and other actors, beyond traditional education and extension work, would strengthen at least one pathway towards turning actionable knowledge into knowledge-inuse. Furthermore, this interface offers opportunities (and potentially risks) for researchers to make science more transparent and discuss the validity and application of their work. As Lang and Wiek (2021) say, more and more venues for joint learning are emerging, and experiences from these may cause research to think through just how we ask and answer questions. 


\section{REFERENCES}

Brix, H., and H.-H. Schierup. 1989. The use of aquatic macrophytes in water-pollution control. Ambio 28: 100-107. https://doi.org/ $10.2307 / 4313539$.

Cassman, K.G., and A. Dobermann. 2021. Nitrogen and the future of agriculture: 20 years on. 50th Anniversary Collection: Solutionsoriented research. Ambio Volume 50. https://doi.org/10.1007/ s13280-021-01526-w.

Cassman, K.G., A. Dobermann, and D.T. Walters. 2002. Agroecosystems, nitrogen-use efficiency, and nitrogen management. Ambio 31: 132-140. https://doi.org/10.1579/0044-7447-31.2. 132.

Falkenmark, M. 1989. The massive water scarcity now threatening Africa: Why isn't it being addressed? Ambio 18: 112-118.

Falkenmark, M. 2021. Planning of Africa's land/water future: Hard or soft landing? 50th Anniversary Collection: Solutions-oriented research. Ambio Volume 50. https://doi.org/10.1007/s13280021-01527-9.

Folke, C., and N. Kautsky. 1989. The role of ecosystems for a sustainable development of aquaculture. Ambio 18: 234-243. https://doi.org/10.2307/4313572.

Folke, C., and N. Kautsky. 2021. Aquaculture and ocean stewardship. 50th Anniversary Collection: Solutions-oriented research. Ambio Volume 50. https://doi.org/10.1007/s13280-021-01528-8.

Lang, D., and A. Wiek. 2021. Structuring and advancing solutionoriented research for sustainability. 50th Anniversary Collection: Solutions-oriented research. Ambio Volume 50. https://doi.org/ 10.1007/s13280-021-01537-7.

Mach, K.J., M.C. Lemos, A.M. Meadow, C. Wyborn, N. Klenk, J.C. Arnott, N.M. Ardoin, C. Fieseler, et al. 2020. Actionable knowledge and the art of engagement. Current Opinion in Environmental Sustainability 42: 30-37. https://doi.org/10.1016/ j.cosust.2020.01.002.

Miller, T.R., A. Wiek, D. Sarewitz, J. Robinson, L. Olsson, D. Kriebel, and D. Loorbach. 2014. The future of sustainability science: A solutions-oriented research agenda. Sustainability Science 9: 239-246. https://doi.org/10.1007/s11625-013-0224-6.

Nepstad, D., C. Uhl, and E.A.S. Serrao. 1991. Recuperation of a degraded Amazonian landscape: Forest recovery and agricultural restoration. Ambio 6: 248-255. https://doi.org/10.5363/tits.6.3_ 37.

Tengö, M., and E. Andersson. 2021. Solutions-oriented research for sustainability: Turning knowledge into action. 50th Anniversary Collection: Solutions-oriented research. Ambio Volume 50. https://doi.org/10.1007/s13280-020-01492-9.

Wiek, A., and D.J. Lang. 2016. Transformational sustainability research methodology. In Sustainability science, ed. H. Heinrichs, P. Martens, G. Michelsen, and A. Wiek, 31-41. Dordrecht: Springer. https://doi.org/10.1007/978-94-017-7242-6_3.

Publisher's Note Springer Nature remains neutral with regard to jurisdictional claims in published maps and institutional affiliations.

\section{Erik Andersson ( $\square)$}

Address: Stockholm University, 10691 Stockholm, Sweden.

e-mail: erik.andersson@su.se 


\section{The Use of Aquatic Macrophytes in Water-Pollution Control}

\begin{abstract}
Ecosystems dominated by aquatic macrophytes are among the most productive in the world. Aquatic plants possess an outstanding ability for assimilating nutrients and creating favorable conditions for microbial decomposition of organic matter. This ability can be exploited in the restoration process of natural streams, lakes and wetlands, and in wastewater-treatment systems. This paper describes different types of macrophyte-based wastewater-treatment facilities, their treatment capacities and their potential applicability under different climatic conditions. Working experiences from Danish facilities are evaluated. The potential for resource recovery by harvesting and utilization of the plant material produced can be regarded as a step in the direction of a holistic solution, where waste products will be regarded and utilized as a resource.
\end{abstract}

\section{INTRODUCTION}

Extensive investments in sewage plants during the last two decades have greatly reduced the organic loading of receiving water bodies in a number of countries. However, an equivalent improvement in water quality has not been achieved since there are many small contributors which still have no cleaning of their wastewater discharge, and since leakage of nitrogen from the agricultural land, as a consequence of the increased use of fertilizers, has greatly increased over the last thirty years (1). Furthermore, only few of the existing wastewater-treatment plants are equipped to remove the nutrients nitrogen and phosphorus. In the early eighties, the local municipalities in Denmark were met with increasing demands for the removal of nitrogen and phosphorus as well as the organic content of the wastewater prior to disposal. The traditional solution for smal contributors is to collect the sewage from several small villages in one central-treatment facility. Such a solution is, however, rather expensive, and therefore the municipalities were, and still are, searching for more cost-effective solutions.

Shallow, eutrophic, aquatic ecosystems stocked with macrophytes are among the most productive in the world (2). The capacity of such systems to decompose organic matter and assimilate nutrients has long been recognized, and it is well known that streams, lakes, coastal areas, and wetlands contain a considerable "self-purification" capacity (3). During the growing season the plants absorb and incorporate the nutrients into their own structures and function as a substrate for microorganisms.

On an international basis, considerable attention is at present being directed towards the capacity of aquatic macrophytes (swamp and water plants) to control pollution and to treat municipal and industrial wastewater as indicated by the great number of participants at recent international meetings (4-6). This interest is partly coupled to the public demand for increasing stringent water-quality standards, and partly to the need to develop low-cost decentralized constructions capable of serving small to medium-sized communities. Macrophyte-based wastewatertreatment systems have several potential advantages compared to conventional treatment systems (7):

- Low operating costs.

- Low energy requirements.

- They can often be established at the site where the wastewater is produced

- They are more flexible and less susceptible to shock loading. H. Brix.
The potential for resource recovery by harvesting and utilizing the biomass produced as an energy source, as compost or as animal fodder should also be emphasized (8). The major disadvantage of macrophyte-based systems is the increased land area required, compared to conventional systems, and decreased performance during winter in temperate regions. Macrophyte-based systems are especially suitable for smaller contributors such as small villages, single farms, camping sites, summer-house areas, and small industries.

\section{WATER-QUALITY IMPROVEMENTS IN}

\section{NATURAL ECOSYSTEMS}

The disposal of large amounts of sewage and the intensified exploitation of agricultural land involving increased amounts of fertilizers, has resulted in pronounced eutrophication of receiving waters. The effects of eutrophication, i.e. lower species diversity and decreasing self-purification capacity, have been greatly magnified by destruction of the natural physical heterogeneity of the ecosystem. Streams have been viewed simply as conduits and have been deepened and straightened and their vegetation has been removed to augment the drainage of agricultural land. Natural wetlands and marshes have been drained and turned into agricultural land.

Regulation of the main tributary to Lake Balaton (Hungary) has resulted in poor water quality in the lake. The dams enclosing the river have now been removed in an attempt to establish a system of shallow macrophyte-dominated reservoirs as a buffering zone for the river water prior to entering the lake. Photo:

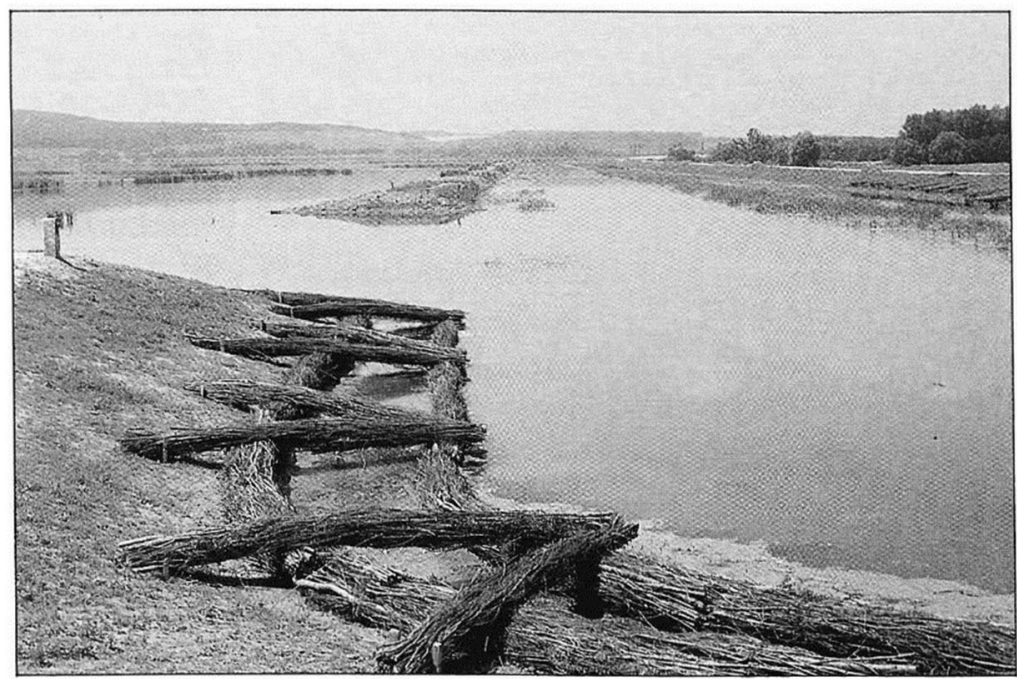




\section{The Massive Water Scarcity Now Threatening Africa - Why Isn't It Being Addressed?}

Ways have to be found to improve life quality and food security in Africa's semiarid countries, despite the environmental constraints of hydroclimatically-induced water scarcity and the considerable interannual fluctuations which characterize the natural freshwater supply. A water-stress profile is presented on a) the role of improved water supply for self-sufficient crop production and b) the number of individuals jointly depending on each flow unit of water available to the country from the water cycle. In a medium-term-perspective, water will not be readily available to support improved life quality for growing African populations. There is an urgent need for increased awareness among African leaders so that adequate strategies can be made for development under conditions of severe water scarcity. Such strategies are urgently needed to stop the present multi-risk spiral from producing repeated collapses during recurrent drought years.

\section{INTRODUCTION}

The last decades have brought the plague of extended drought to many African countries. The 1984-1985 drought generated an international plea in the United Nations for food supplies and other forms of relief to reduce famine in some 20 African countries. In late 1987, a new drought took its toll in Ethiopia.

These occurrences have indicated that not only lack of water but also large interannual fluctuations may generate largescale, region-wide problems, and even cause emigration of environmental refugees. This picture contradicts the notion of Africa as a continent rich in water reserves (1). It could be that temperate zone experts are in fact poor advisers, as they

Figure 1. The global water-circulation system (a) brings water to the continents (b), wetting them and feeding their ecosystems (c). The surplus not returning to the atmosphere in the short branch of the water cycle recharges terrestrial water systems in aquifers and rivers (the long branch).

a

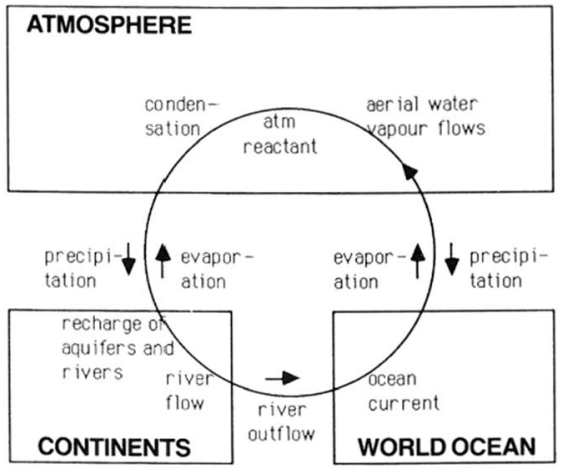

b

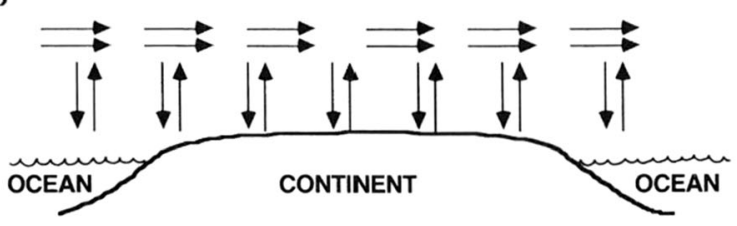

c

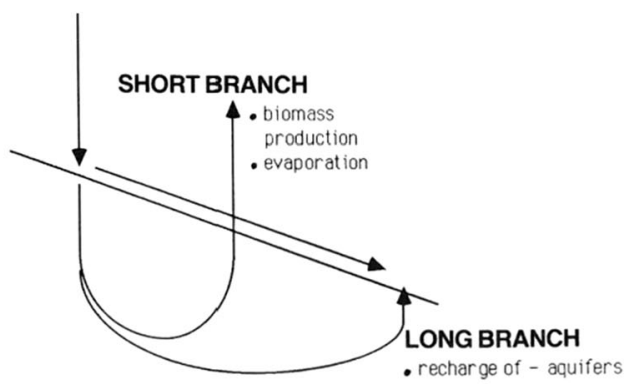

- rivers 


\section{The Role of Ecosystems for a Sustainable Development of Aquaculture}

This paper discusses the basis for cage culturing of salmonids and mussel long-line rearing in Scandinavian marine aquaculture, it also includes a discussion on the support that is required from the marine environment to sustain production; how aquaculture fits into the marine ecosystem; and what side-effects and changes it may cause. Local as well as regional environmental effects are evaluated and related to the growth and economic development of the aquaculture industry. While mussel-rearing represents a more or less self-regulated extensive aquaculture system that is, to a large extent, integrated with the natural marine ecosystem, cagefarming of fish has a processing structure which resembles modern intensive meat production. Cage-farming adds to eutrophication due to nutrient input through the supplied feed, while mussel culturing counteracts eutrophication since no feed is added and nutrients are removed when the mussels are harvested. The production of 1 ton of harvested farmed salmon is indirectly (via food pellets mainly made from fish) dependent on solar fixation by marine plankton from a water area of about $1 \mathrm{~km}^{2}$, while the production of 1 ton of harvested mussels needs about only one thousandth of this area. The support from marine and agricultural ecosystems needed to provide the farming of salmonids with food is estimated (in energy terms) to be about 6 times larger than the contributions of all industrial activities directly or indirectly involved with the cage-farming. The development of a sustainable aquaculture industry implies that culturing has to be carefully dimensioned to the capacity of the ecosystems to support aquaculture production, and should not exacerbate environmental degradation. It is proposed that a combined strategy of culturing mussels and salmonids would be one way towards this goal.

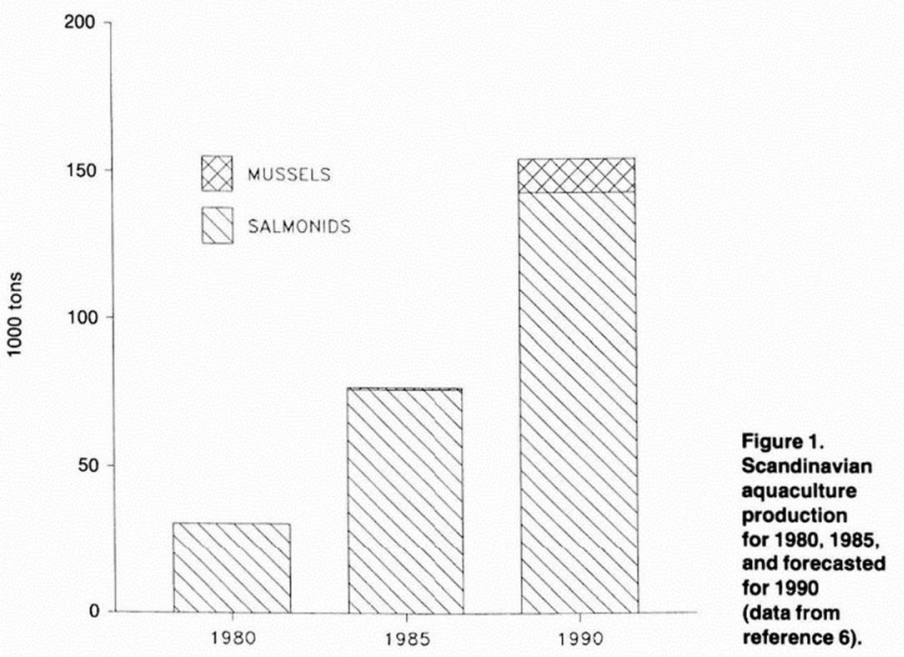

\section{INTRODUCTION}

Studies of man's influence on the environment are increasing. However, the role of the natural environment in sustaining industrial activity is rarely appreciated or recognized. The economic significance of this support is often first perceived when the ecosystem becomes degraded. Instead of exploiting the natural ecosystem and using it for waste disposal in order to expand industry it will, in several cases, be necessary to manage the ecosystem in order to maintain a specific industry. This may create ecological, economic, and social problems in adapting to the new conditions $(1,2)$

Producing food by aquaculture is in many respects comparable to agricultural food production. Methods of cultivation vary from intensive farming requiring auxiliary inputs and capital, such as salmonid cage-farming, to extensive rearing systems, such as mussel culturing, which are to a great extent run by natural processes. The Brundtland Report (3) emphazises that to make sustainable $(4,5)$ food production possible, development and environmental concern must go hand in hand. Environmental aspects of salmonid cage-farming or mussel-rearing usually focus largely on the rearing site, indepen-

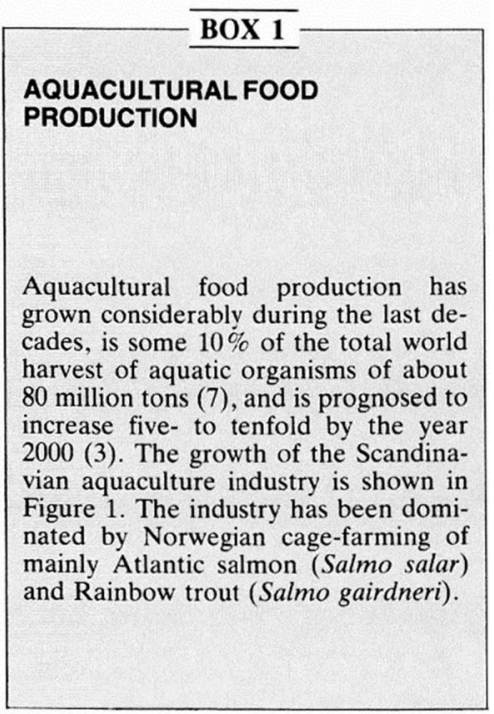

AMBIO VOL, 18 NO 4,1989 


\section{Recuperation of a Degraded Amazonian Landscape: Forest Recovery and Agricultural Restoration}

Ranching and logging operations are transforming the moist tropical forests of an eastern Amazonian landscape into a mosaic of pastures and regrowth forests. The new ecosystems of this region are agriculturally unproductive, biologically impoverished, and far more flammable than the mature forests they replace; hydrologic differences between the new and old ecosystems are unknown and potentially large. In the absence of fire, the forest regrows on abandoned sites, accumulating biomass and species at a rate that is inversely related to the intensity of use prior to abandonment. Forest regrows slowest on those rare abandoned pastures that were once scraped with bulldozers. The grass- and shrub-dominated old fields that form on some of these sites resist forest regrowth because of numerous barriers to tree establishment and growth, including: low propagule availability, seed predation, seedling predation, seasonal drought, and root competition with old field vegetation. Knowledge of these barriers provides a basis for developing inexpensive techniques to restore agricultural productivity in old fields by implanting tree-based agricultural systems or to restore forest regenerative capacity in old fields by establishing trees that attract seed-carrying animals and ameliorate harsh environmental conditions. These restoration techniques will be needed over large areas of Amazonia if current attempts to reform degraded pastures fail. dominated old fields, a new ecosystem that is resistant to forest regrowth, and incorporate this information into strategies for restoring agricultural productivity and forest structure and function in old fields.

\section{FOREST TRANSFORMATION IN THE PARAGOMINAS LANDSCAPE}

The completion in 1964 of the $1900 \mathrm{~km}$, allweather road connecting the city of Belém, at the mouth of the Amazon river, with Brasília, the nation's capital, marked the beginning of large-scale immigration to Amazonia and heralded a wave of forest transformation. Hundreds of thousands of people and firms were lured to eastern Amazonia by the new road and by governmentfinancial incentives. Most of the early newcomers to Amazonia settled in the state of Pará and began to derive their

\section{INTRODUCTION}

People are transforming the forests of Amazonia into regrowth forests and open fields. The long-term impact of this transformation on soil fertility, hydrology, biotic diversity and the concentration of heatcapturing gases in the atmosphere depends on the structural and functional differences between the original forests and the ecosystems that are replacing them. Strategies to conserve the regulatory functions performed by Amazon forests and the species of which they are composed must therefore look beyond the conservation of pristine forest reserves and consider the new ecosystems that are coming to dominate Amazonian landscapes. Strategies to increase the agricultural productivity of Amazonian lands should focus on restoration of productivity on abandoned sites.

The forests of the Paragominas region in eastern Amazonia have been transformed by ranching and logging activities for more than 20 years and may provide a glimpse into the future of other regions of agricultural frontier expansion in Amazonia. In this article, we describe the ecosystems that are created by ranching and logging activities in the Paragominas landscape, and the patterns of forest regrowth observed in each ecosystem. We then discuss the barriers to tree establishment in grass- and shrub-

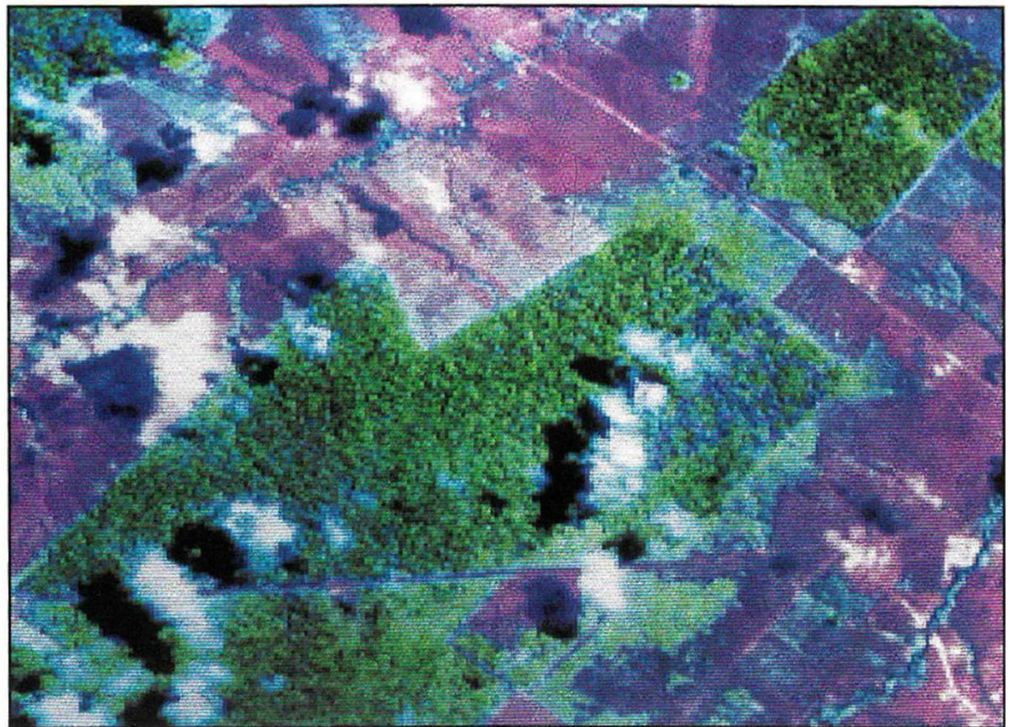

Satellite image (LANDSAT Thematic Mapper, Band 3,4,5, $7 \times 7 \mathrm{~km}$ ) of the Paragominas landscape as it appeared in 1988. The dark green matrix of virgin forest is surrounded by the violet trails of logging operations (center right), the light green of regrowth forests on abandoned pastures, the dark pinks and violets of degraded pastures, the light pinks and violets of reformed pastures (made more distinct by parallel lines-windrows of organic debris and soil formed by bulldozers). The edge of the town of Paragominas appears in the lower right and a black pepper plantation is visible as a violet rectangle (lower center). Clouds are bright white and their adjacent shadows are black. 


\section{Agroecosystems, Nitrogen-use Efficiency, and Nitrogen Management}

The global challenge of meeting increased food demand and protecting environmental quality will be won or lost in cropping systems that produce maize, rice, and wheat. Achieving synchrony between $\mathrm{N}$ supply and crop demand without excess or deficiency is the key to optimizing tradeoffs amongst yield, profit, and environmental protection in both large-scale systems in developed countries and smallscale systems in developing countries. Setting the research agenda and developing effective policies to meet this challenge requires quantitative understanding of current levels of $\mathrm{N}$-use efficiency and losses in these systems, the biophysical controls on these factors, and the economic returns from adoption of improved management practices. Although advances in basic biology, ecology, and biogeochemistry can provide answers, the magnitude of the scientific challenge should not be underestimated because it becomes increasingly difficult to control the fate of $N$ in cropping systems that must sustain yield increases on the world's limited supply of productive farm land.

\section{INTRODUCTION}

The focus of this paper is on nitrogen-use efficiency (NUE) in cereal production systems because maize (Zea mays L.), rice (Oryza sativa L.), and wheat (Triticum aestivum L.) provide more than $60 \%$ of human dietary calories either as cereals for direct human consumption or embodied in livestock products produced from animals fed with feed grains and their by-products (http:/apps.fao.org/, agricultural production). It is likely that these same cereal crops will continue to account for the bulk of the future human food supply because they produce greater yields of human-edible food, are easily grown, stored, and transported, and require less fuel and labor for processing and cooking than other food crops. Our analysis will examine the NUE of these primary cereals in the world's major cropping systems, which also account for the majority of global $\mathrm{N}$ fertilizer use. We define the NUE of a cropping system as the proportion of all $\mathrm{N}$ inputs that are removed in harvested crop biomass, contained in recycled crop residues, and incorporated into soil organic matter and inorganic $\mathrm{N}$ pools. Nitrogen not recovered in these $\mathrm{N}$ sinks is lost from the cropping system and thus contributes to the reactive $\mathrm{N}(\mathrm{Nr})$ (1) load that cascades through environments external to the agroecosystem.

Our evaluation will focus on NUE in on-farm settings because estimates of NUE from experimental plots do not accurately represent the efficiencies achieved in farmers' fields. This lack of agreement results from differences in the scale of farming operations and differences in N-management practices-some of which are only feasible in small research plots. The effect of scale not only influences $\mathrm{N}$ fertilizer application, but all other management operations such as tillage, seeding, weed and pest management, irrigation, and harvest, which also affect efficiency. As a result, $\mathrm{N}$-fertilizer efficiency in well-managed research experiments is generally greater than the efficiency of the same practices applied by farmers in production fields. For example, the average $\mathrm{N}$-fertilizer uptake efficiency (defined as the percent- age of fertilizer- $\mathrm{N}$ recovered in aboveground plant biomass during the growing season-hereafter called the $\mathrm{N}$-fertilizer recovery efficiency $-\mathrm{RE}_{\mathrm{N}}$ ), achieved by rice farmers is $31 \%$ of applied $\mathrm{N}$ based upon on-farm measurements in the major rice-production regions of four Asian countries (Table 1). In contrast, $\mathrm{RE}_{\mathrm{N}}$ for rice in well-managed field experiments typically range from $50-80 \%(3-5)$. In the authors' experience, similar overestimation of $\mathrm{RE}_{\mathrm{N}}$ in small plot experiments occurs for irrigated and rain-fed maize in the North-Central USA and for irrigated wheat in California.

The need to improve $\mathrm{RE}_{\mathrm{N}}$ will be emphasized because $\mathrm{N}$ fertilizer is the largest source of $\mathrm{N}$ input to and losses from cereal cropping systems. A recent study estimates total $\mathrm{N}$ input to the world's cropland at $169 \mathrm{Tg} \mathrm{N} \mathrm{yr}^{-1}$ (6). Inorganic $\mathrm{N}$ fertilizer, biological $\mathrm{N}$ fixation from legumes and other $\mathrm{N}$-fixing organisms, atmospheric deposition, animal manures, and crop residues account for $46 \%, 20 \%, 12 \%, 11 \%$, and $7 \%$, respectively, of this total. Hence, crop-management practices that increase $\mathrm{RE}_{\mathrm{N}}$ have a substantial impact on the amount of $\mathrm{Nr}$ that escapes from cereal production systems. While we recognize that solutions to global concerns about effects of $\mathrm{Nr}$ on the environment must involve integrated management of both inorganic and organic $\mathrm{N}$ sources to maximize NUE, other papers in this issue of Ambio and elsewhere address issues of $\mathrm{N}$ efficiency in livestock production systems and the contributions of organic $\mathrm{N}$ sources such as legume crops and green manures $(6,7)$.

\section{NITROGEN-USE EFFICIENCY TODAY}

Applied N not taken up by the crop or immobilized in soil organic $\mathrm{N}$ pools-which include both microbial biomass and soil organic matter-is vulnerable to losses from volatilization, denitrification, and leaching. The overall NUE of a cropping system can therefore be increased by achieving greater uptake efficiency from applied $\mathrm{N}$ inputs, by reducing the amount of $\mathrm{N}$ lost from soil organic and inorganic $\mathrm{N}$ pools, or both. In many cropping systems, the size of the organic and inorganic $\mathrm{N}$ pools has reached steady-state or is changing very slowly, and the $\mathrm{N}$ inputs from biological $\mathrm{N}_{2}$ fixation and atmospheric deposition are relatively constant. For example, analysis of the $\mathrm{N}$ balance in long-term experiments on irrigated rice in Asia suggests that many of these systems have reached steady-state (8), and similar evidence suggests that some maize-based cropping systems in the USA corn belt are also near steady-state (9). In these cases, the overall NUE of a cereal cropping system is equal to the $\mathrm{RE}_{\mathrm{N}}$.

In contrast to systems at steady-state, adoption of new management practices or crop rotations that affect the soil carbon (C) balance will also affect the $\mathrm{N}$ balance because the $\mathrm{C} / \mathrm{N}$ ratio of soil organic matter is relatively constant. In such cropping systems, the overall NUE of the cropping system must include changes in the size of soil organic and inorganic $\mathrm{N}$ pools in addition to the $\mathrm{RE}_{\mathrm{N}}$. When soil- $\mathrm{N}$ content is increasing, the amount of sequestered $\mathrm{N}$ contributes to a higher NUE of the cropping system, and the amount of sequestered $\mathrm{N}$ derived from applied $\mathrm{N}$ contributes to a higher $\mathrm{RE}_{\mathrm{N}}$. Conversely, any decrease in soil$\mathrm{N}$ stocks will reduce $\mathrm{NUE}$ and $\mathrm{RE}_{\mathrm{N}}$.

Unfortunately, there is a paucity of reliable data on $\mathrm{RE}_{\mathrm{N}}$ based 